\title{
Betulinic acid induces apoptosis by regulating PI3K/Akt signaling and mitochondrial pathways in human cervical cancer cells
}

\author{
TAO XU $\mathrm{X}^{12^{*}}$, QIUYING PANG ${ }^{1,2^{*}}$, YANG WANG $^{1,2}$ and XIUFENG YAN ${ }^{1,2}$ \\ ${ }^{1}$ Alkali Soil Natural Environmental Science Center, Northeast Forestry University; ${ }^{2}$ Key Laboratory of Saline-alkali \\ Vegetation Ecology Restoration, Ministry of Education, Harbin, Heilongjiang 150040, P.R. China
}

Received February 16, 2017; Accepted September 19, 2017

DOI: $10.3892 / \mathrm{ijmm} .2017 .3163$

\begin{abstract}
Betulinic acid(BA), a potential anticancercompound, could induce apoptosis in human cervical cancer (HeLa) cells, but its mechanism has yet to be fully elucidated. The present study was focused on deciphering the detailed molecular mechanism of BA-induced apoptosis. In the present study, results indicated that BA was highly effective against HeLa cells via induction of time-dependent apoptosis, and the authors demonstrated that the BA treatment acted through downregulating a phosphatidylinositol 3-kinase (PI3K) subunit and suppressing the Akt phosphorylation at Thr308 and Ser473 after increasing the generation of intracellular reactive oxygen species. Then, BA induced cell cycle arrest at the G0/G1 phase, which was consistent with the cell cyclerelated protein results in which BA significantly enhanced the expression of $\mathrm{p} 27^{\mathrm{Kip}}$ and $\mathrm{p} 21^{\text {Waf1/Cipl }}$ in HeLa cells. This target-specific inhibition was associated with mitochondrial apoptosis, as reflected by the increased expression of Bad and caspase-9, the generation of reactive oxygen species (ROS) and the decline in mitochondrial membrane potential. Moreover, preincubation of the cells with glutathione (antioxidant) blocked the process of apoptosis, prevented the phosphorylation of downstream substrates. These results established that ROS acted as a key factor to effect apoptosis by BA treatment in HeLa cells. Therefore, these findings demonstrated that BA induced apoptosis in HeLa cells by downregulating the expression of PI3K/Akt signaling molecules via ROS, and triggering a mitochondrial pathway.
\end{abstract}

\section{Introduction}

Betulinic acid (BA) (Fig. 1A) is a naturally occurring lupanetype triterpene found in the bark of white birch trees, and it

Correspondence to: Dr Xiufeng Yan, Alkali Soil Natural Environmental Science Center, Northeast Forestry University, Harbin, Heilongjiang 150040, P.R. China

E-mail:xfyan@nefu.edu.cn

*Contributed equally

Key words: betulinic acid, HeLa cells, PI3K/Akt signaling pathway, mitochondrial pathway, reactive oxygen species is one of the most promising lead compounds for new cancer therapeutics (1). BA has been introduced as a potential anticancer compound against a wide variety of cancer cells such as leukemia, prostate, ovarian, breast, lung and hepatoblastoma (2-5). This anticancer activity has been linked to its ability to directly trigger mitochondrial membrane permeabilization independent of p53, a central event in the apoptotic process in many cancer cells (6-8). However, the mechanism by which BA induces apoptosis in human cervical cancer has yet to be fully elucidated.

Triterpenoids have been reported to induce cell cycle arrest and apoptosis via modulation of the phosphatidylinositol 3-kinase (PI3K)/Akt pathway (9), which is an intracellular signaling pathway important in regulating several cellular processes. Activation of the PI3K/Akt pathway has been shown to promote cellular survival in a vast of cancer cells, because it can inhibit the cell cycle progression by repressing downstream factors: $\mathrm{p} 27^{\mathrm{Kip}}$ and $\mathrm{p} 21^{\text {Waf1/Cip1 }}$ belong to cyclin-dependent kinase $(10,11)$. At the same time, it also can modulate apoptosis by phosphorylating and inactivating several targets, like Bad and caspase-9, that have important roles in mitochondrial apoptosis pathways (12). Apoptosis induced by BA involves activation of caspases, was suggested to depend on the mitochondrial pathway, therefore, the authors hypothesized that the PI3K/Akt pathway may involve in the apoptosis process by BA induction (13).

In a previous study, it was demonstrated that BA can induce apoptosis activity in HeLa by proteomic (14), but the molecular mechanisms behind its function are still not fully understood. In the present study, the authors attempted to evaluate the mechanistic role of BA in a cervical cancer cell line (HeLa) by exploring its effects on apoptosis and the cell cycle. In addition, they attempted to investigate the important signaling network, such as the PI3K/Akt signaling pathway and the mitochondrial pathway involved in BA treatment in HeLa cells. The aim of the present study was to better understand the apoptosis mechanism induced by BA.

\section{Materials and methods}

Antibodies and reagents. BA powder was purchased from Shanghai Boyle Chemical Co., Ltd. (Shanghai, China) and dissolved in dimethylformamide. Primary antibodies were purchased from Cell Signaling Technology, Inc. (Danvers, 
MA, USA): anti-PI3K p85 (cat. no. 4257), anti-PI3K p110a (cat. no. 4249), anti-Akt (cat. no. 4691), anti-phospho-Akt (Thr308) (cat. no. 2965), anti-phospho-Akt (Ser473) (cat.no.4060), anti-Bcl-xL (cat.no.2764), anti-Bad (cat.no.9292), anti-caspase-9 (cat. no. 9501), anti-p21 ${ }^{\text {Waf1/Cip1 }}$ (cat. no. 2947), anti-p27 ${ }^{\text {Kip }}$ (cat. no. 2552) and anti- $\beta$-actin (cat. no. 4970). Peroxidase-conjugated goat anti-rabbit $\operatorname{IgG}(\mathrm{H}+\mathrm{L})$ was from Santa Cruz Biotechnology, Inc. (Dallas, Texas, USA) and SuperSignal West Femto Maximum Sensitivity Substrate from Thermo Fisher Scientific, Inc. (Waltham, MA, USA). Wortmannin and reduced L-glutathione (GSH) was purchased from Sigma-Aldrich; Merck KGaA (Darmstadt, Germany).

Cell culture. The human cancer cell line HeLa was purchased from the Tumor Center (Beijing Yinzijing Biological Company, Beijing, China). Cells were cultured in RPMI-1640 medium (HyClone; GE Healthcare Life Sciences, Chalfont, UK) with 10\% fetal bovine serum (FBS; GE Healthcare Life Sciences), $100 \mathrm{U} / \mathrm{ml}$ penicillin and $100 \mu \mathrm{g} / \mathrm{ml}$ streptomycin (HyClone; GE Healthcare Life Sciences). Cells were seeded in 6-, 12- and 96-well microplates and then incubated at $37^{\circ} \mathrm{C}$ in $5 \% \mathrm{CO}_{2}$. The control group was HeLa cells with a corresponding concentration of DMF, such as $30 \mu \mathrm{mol} / 1 \mathrm{BA}$ corresponding control group is $0.15 \% \mathrm{DMF}$ in medium. The concentration of probe drug is $20 \mathrm{mmol} / \mathrm{l}$.

Cell proliferation assay (MTT assay). Cells $\left(2 \times 10^{4} / \mathrm{ml}\right)$ were seeded in 96-well microplates and then incubated at $37^{\circ} \mathrm{C}$ in $5 \% \mathrm{CO}_{2}$. At $24 \mathrm{~h}$, the medium was removed and replaced with fresh medium containing various concentrations of BA for various periods of time. Next, $30 \mu \mathrm{l}$ of $3 \mathrm{mg} / \mathrm{ml} \mathrm{MTT}$ (Amresco, Inc., Framingham, MA, USA) in phosphate-buffered saline (PBS) was added to each well, and then the plate was further incubated for $4 \mathrm{~h}$. The remaining supernatant was removed, and $150 \mu \mathrm{l}$ DMSO was added to each well and mixed thoroughly to dissolve the formazan crystals that formed. After 10 min incubation, the absorbance of each well was read at $490 \mathrm{~nm}$ using a BioTek-ELISA plate reader (BioTek Instruments, Inc., Winooski, VT, USA).

Detection of morphological changes. To detect morphological changes that occurred during apoptosis process, nuclear staining was performed using a $5 \mu \mathrm{g} / \mathrm{ml}$ Hoechst 33258 (Sigma-Aldrich; Merck KGaA) stain, and samples were visualized using a Nikon fluorescence microscope (Eclipse Ti-S; Nikon Corp., Tokyo, Japan).

Flow cytometry analysis of cell apoptosis. BA-induced apoptosis was observed by Annexin V-fluorescein isothiocyanate (FITC)/propicium iodide (PI) staining (Beyotime Institute of Biotechnology, Haimen, China) according to the manufacturer's instructions. Flow cytometry (BD FACSCanto; BD Biosciences, Franklin Lakes, NJ, USA) was used to analyze differences in apoptosis between control and BA-treated for various periods of time cells at $48 \mathrm{~h}$ post treatment. Cells were collected and analyzed by counting normal cells, early-stage apoptotic cells and late-stage apoptotic/necrotic cells in three fields of view of the microscope. The data acquisition and analysis were performed using BD FACSDiva software (version A, BD FACSCanto; BD Biosciences, Franklin Lakes, NJ, USA).
Western blot assay. HeLa cells $\left(1.7 \times 10^{5}\right)$ were seeded in 6-well microplates before treatment with BA or wortmannin (a specific inhibitor of PI3K) at the concentration of $30 \mu \mathrm{mol} / 1$ for $6 \mathrm{~h}$ time period. Wortmannin was used as a positive control here. Cells were collected and lysed in RIPA buffer (Beyotime Institute of Biotechnology) with PhosSTOP phosphatase inhibitor cocktail tablets (Roche Diagnostics, Indianapolis, IN, USA). Equal amounts of protein ( $30 \mu \mathrm{g} /$ lane) by Bradford were separated by $12 \%$ sodium dodecyl sulfate-polyacrylamide gel electrophoresis (SDS-PAGE) and transferred to a polyvinylidene difluoride membrane (EMD Millipore, Billerica, MA, USA). After blocking in 5\% non-fat milk and washing, the blots were incubated overnight at $4^{\circ} \mathrm{C}$ with specific primary antibodies diluted to 1:1,000 following the CST protocol. The membrane was washed three times with Tris-buffered saline (containing 1\% Tween-20), and then incubated with secondary antibodies (peroxidase-conjugated goat anti-rabbit IgG $(\mathrm{H}+\mathrm{L})$ diluted to $1: 8,000$ for $1 \mathrm{~h}$, followed with the same washing steps as above. Then, the immunoreactive proteins were visualized using the enhanced chemiluminescence reagent. Image Lab software (version 3.0; Bio-Rad, Hercules, CA, USA) was used to quantify of proteins using $\beta$-actin as a loading control. Changed fold was represented by the protein expression ratio [(target protein/ $\beta$-actin)/the control group].

Measurement of oxidative stress. The levels of intracellular ROS were determined using a ROS assay kit (Beyotime Institute of Biotechnology) following the manufacturer's protocol. Cells were harvested after various periods of time $(0-48 \mathrm{~h})$ of $30 \mu \mathrm{mol} / 1 \mathrm{BA}$ treatment and then washed twice with PBS and incubated with DCFH-DA $(10 \mu \mathrm{mol} / \mathrm{l})$ at $37^{\circ} \mathrm{C}$ for $40 \mathrm{~min}$ in a darkroom for final analysis by flow cytometry.

Measurement of mitochondrial membrane potential (MMP). MMP was determined using JC-1 probe (Beyotime Institute of Biotechnology) as described previously (15). Briefly after treating the cells with $30 \mu \mathrm{mol} / \mathrm{l} \mathrm{BA}$ for various periods of time $(0-48 \mathrm{~h})$, cells were stained with $0.5 \mathrm{mg} / \mathrm{ml}$ of the fluorescence probe $\mathrm{JC}-1$ for $20 \mathrm{~min}$ at $37^{\circ} \mathrm{C}$. After washing, cells were analyzed for the decrease in red/green fluorescence by flow cytometry. The mitochondrial membrane potential is indicated by a decrease in red/green fluorescence intensity ratio.

Cell cycle analysis. HeLa cells were harvested via trypsin after $30 \mu \mathrm{mol} / 1 \mathrm{BA}$ for different time treatment, washed with PBS and fixed with $70 \%$ ethanol at $4^{\circ} \mathrm{C}$ for overnight. After washing twice with PBS, cells were stained with cell cycle analysis kit (Beyotime Institute of Biotechnology) containing propidium iodide (PI) and RNase A for $30 \mathrm{~min}$ in the dark at room temperature, as described previously (16). The DNA contents for cell cycle phase distribution were analyzed by Modfit LT 3.2 software (Verity Software House, Topsham, ME, USA).

ROS inhibitor treatment. In order to investigate the contribution of ROS in BA induced apoptosis, GSH, a ROS scavenger, was used as an ROS inhibitor. HeLa cells were seeded in 6 -well plates $\left(1.7 \times 10^{5}\right.$ cells/well) for $24 \mathrm{~h}$, then pre-incubation GSH for $1 \mathrm{~h}$ before treatment with $30 \mu \mathrm{mol} / 1 \mathrm{BA}$ for $6 \mathrm{~h}$, the changes and the percentage of apoptotic cells were examined 


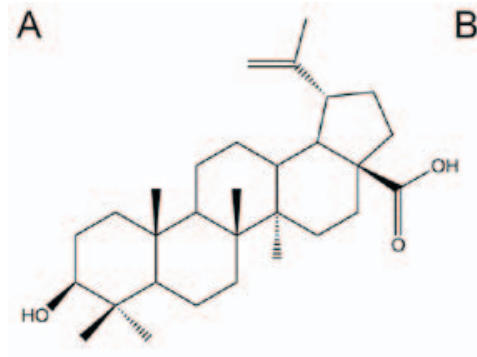

C

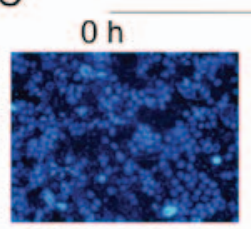

D

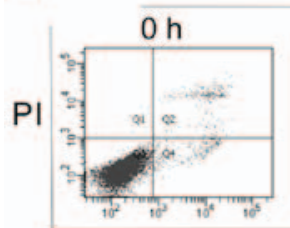

B

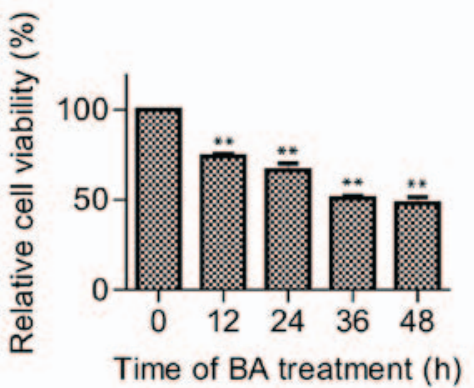

E

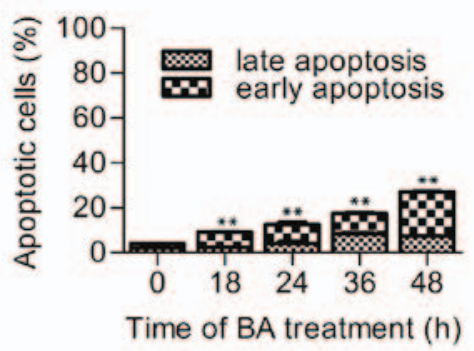

$30 \mu \mathrm{mol} / \mathrm{l} \mathrm{BA}-$ treated HeLa cells
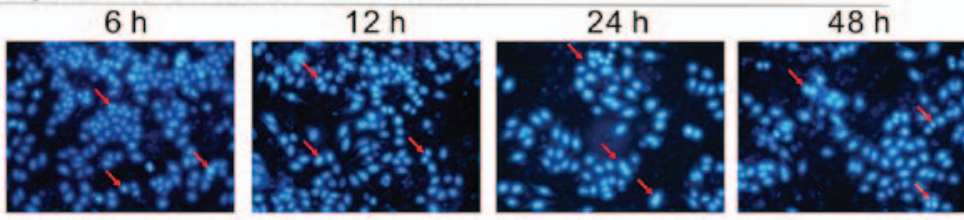

$30 \mu \mathrm{mol} / \mathrm{l} \mathrm{BA}$ - treated HeLa cells
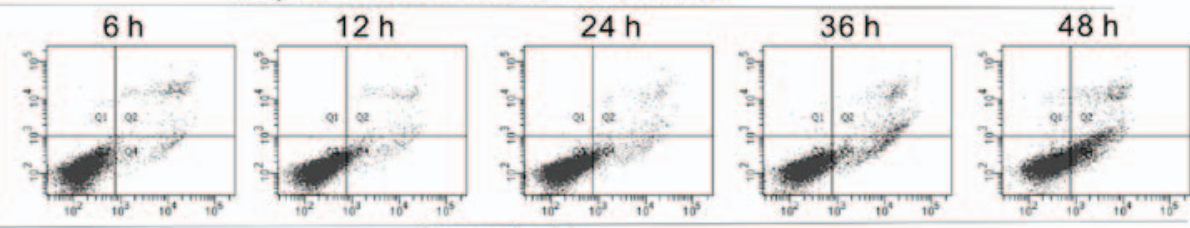

Annexin-V

Figure 1. Effects of BA on the proliferation and apoptosis of HeLa cells. (A) Chemical structure of BA. (B) Cell viability was determined by the MTT assay. Cells were treated with indicated time of BA $(12,24,36$ and $48 \mathrm{~h})$. The values for each BA concentration tested represented the mean of three experiments, data were presented as mean \pm standard deviation. (C) Hoechst 33258-staining of HeLa cells treated with $30 \mu \mathrm{mol} / 1 \mathrm{BA}$ at 3, 6, 12, 24 and $48 \mathrm{~h}$ under a fluorescence microscope at x200 magnification. Red arrows indicate several apoptotic cells with typical condensation of chromatin. (D) Cells were treated with $30 \mu$ mol/1 BA at different time $(6,12,24,36$ and 48 h). (E) Flow cytometric histograms. Columns showed mean values of three experiments, mean \pm standard deviation. ${ }^{* * *} \mathrm{P}<0.01$ vs. control group BA, betulinic acid.

by flow cytometry, as described above. In parallel, western blotting of proteins in PI3K/Akt pathway experiments were accomplished.

Statistical analysis. The data were presented as mean \pm standard deviation and the results were taken from at least three independent experiments. The statistically significant differences were determined using one-way analysis of variance by SPSS software (version 17.0; SPSS, Inc., Chicago, IL, USA). $\mathrm{P}<0.05$ was considered to indicate a statistically significant difference.

\section{Results}

BA inhibited proliferation and induced apoptosis in HeLa cells. The antiproliferative activity induced by BA in HeLa cells was evaluated by an MTT assay. To identify the beginning of apoptosis and morphological changes for further experiment, the authors used flow cytometry and fluorescence microscopy to detect the HeLa cells after incubation with BA (30 $\mu \mathrm{mol} / \mathrm{l}$ ) in a series of time ranging up to $48 \mathrm{~h}$.

The cell viability, as indicated by an MTT assay, displayed a general decline with increasing duration (12, 24, 36 and $48 \mathrm{~h}$ ) of treatment with $30 \mu \mathrm{mol} / 1 \mathrm{BA}$ (Fig. 1B), suggesting that BA inhibited the cell viability of HeLa in a dose-dependent manner; and the $\mathrm{IC}_{50}$ was $66.75 \pm 1.73 \mu \mathrm{mol} / 1,39.75 \pm 2.16 \mu \mathrm{mol} / 1$ and $30.42 \pm 2.39 \mu \mathrm{mol} / 1$ when HeLa cells were treated with BA for 24,36 and $48 \mathrm{~h}$, respectively (the $\mathrm{IC}_{50}$ was $>100 \mu \mathrm{mol} / 1$ for a $12 \mathrm{~h}$ BA treatment). In order to examine the effect of
BA-induced apoptosis in HeLa cells, the typical morphology of apoptosis was detected in BA-treated HeLa cells in more time points, $(3,6,12,24$ and 48 h), as presented in Fig. 1C, the cell counts significantly declined following $12 \mathrm{~h}$. To confirm that the reduction in the cell numbers was reflective of cell death, flow cytometric detection was performed using labeled Annexin V-FITC/PI, did not show a significant change until $12 \mathrm{~h}$ of incubation (little change at $6 \mathrm{~h}$ ). The total percentage of apoptotic cells was $9.53 \pm 1.46 \%(7.2 \pm 1.14 \%$ of cells in early apoptosis and $2.33 \pm 0.25 \%$ of cells in late apoptosis), $13.10 \pm 1.45 \%(9.03 \pm 1.22 \%$ of cells in early apoptosis and $4.07 \pm 1.76 \%$ of cells in late apoptosis), $18.97 \pm 2.25 \%$ $(9.90 \pm 1.30 \%$ of cells in early apoptosis and $9.10 \pm 1.00 \%$ of cells in late apoptosis) and $25.38 \pm 3.42 \%(18.01 \pm 3.38 \%$ of cells in early apoptosis and $7.36 \pm 0.21 \%$ of cells in late apoptosis) for cells treated with $30 \mu \mathrm{mol} / 1 \mathrm{BA}$ for $12,24,36$ and $48 \mathrm{~h}$, respectively (Fig. 1D and E).

Effect of BA on the expression of PI3K and phosphorylated $A k t$. To investigate the involvement of the PI3K/Akt pathway which plays an important role for cell survival and apoptosis, the authors performed a time-dependence study in which HeLa cells were incubated with BA for times ranging from 0-6 h. To select the treatment time for the western blot experiments, the caspase-9 expression was tested firstly, which is a wellestablished role in the process of mitochondrial apoptosis (16). The expression level of caspase- 9 was identified by western blot analysis at a series of time points $(0,1,3,6,12$ and $24 \mathrm{~h})$, as Fig. 2A shown, after stimulation with $30 \mu \mathrm{mol} / 1 \mathrm{BA}$ for $6 \mathrm{~h}$, 
A $\quad$ Treatment (h) $\quad 0 \quad 3 \quad 3 \quad 6 \quad 12 \quad 24$

Cleaved caspase-9
$\beta$-actin

B

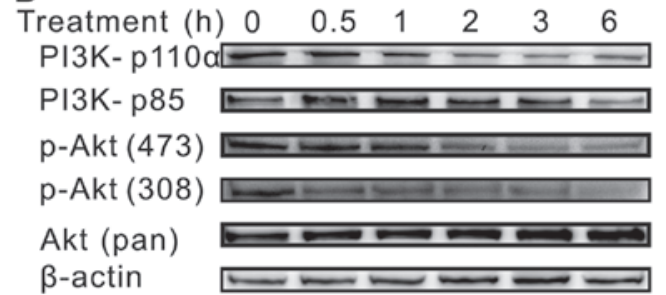

$\mathrm{C}$
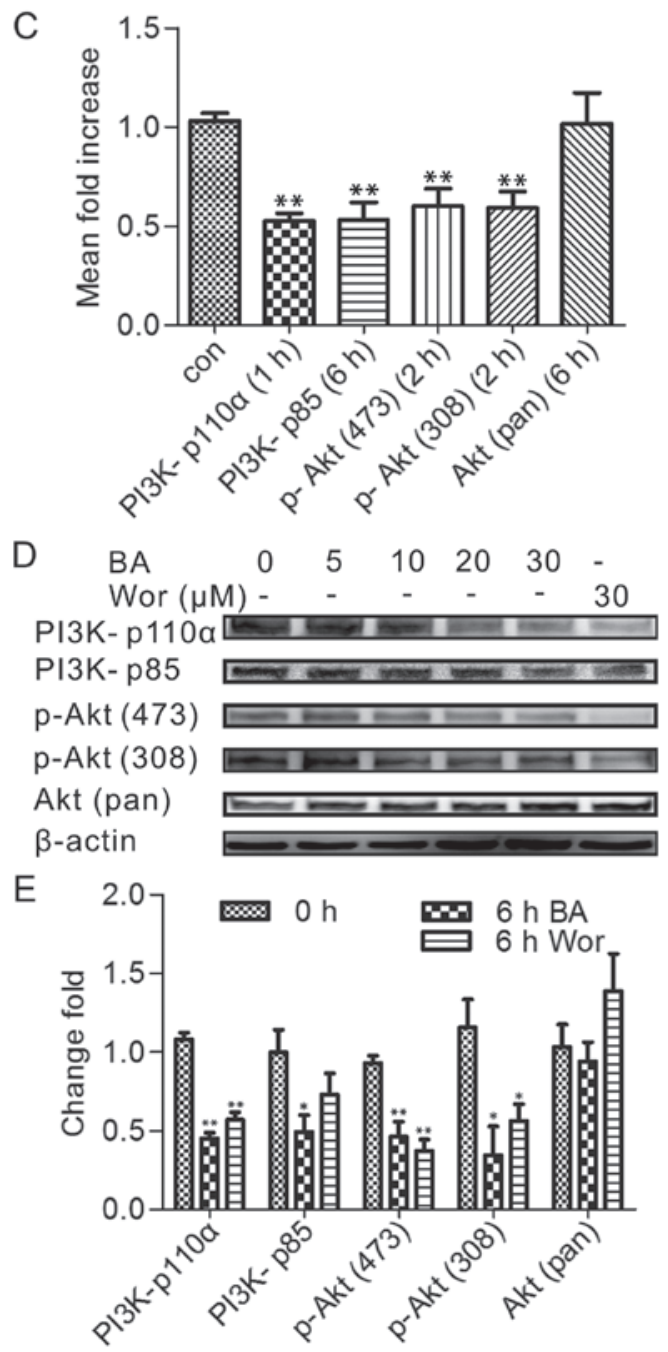

Figure 2. Western blot analysis for the expression of cleaved caspase-9, PI3K (p110a, p85), phospho-Akt (Ser473, Thr308, pan) in BA-treated HeLa cells. (A) The expression of cleaved caspase- 9 was activated by $30 \mu \mathrm{mol} / 1$ BA from $6 \mathrm{~h}$ treatment. (B) Time course $(0-6 \mathrm{~h})$ data revealed PI $3 \mathrm{~K}$ and AKT phosphorylation pattern changed in HeLa cells with $30 \mu \mathrm{mol} / \mathrm{l} \mathrm{BA}$ treatment. (C) Data represented the significant change of initiation time by three independent experiments. (D) Results exhibited the effects of various concentrations of BA $(0-30 \mu \mathrm{mol} / 1)$ or $30 \mu \mathrm{mol} / 1$ wortmannin in a $6 \mathrm{~h}$ incubation period. (E) Three independent experiments were performed in triplicate for each group. Data are presented as the mean \pm standard deviation. Mean fold increase $=[(\operatorname{target}$ protein $/ \beta$-actin $) /$ the control group $]$ ${ }^{*} \mathrm{P}<0.05$ and ${ }^{* *} \mathrm{P}<0.01$ vs. control group $(0 \mu \mathrm{mol} / 1 \mathrm{BA}$ or $0 \mathrm{~h})$. BA, betulinic acid; Wor, wortmannin; con, control.

the cleaved caspase- 9 expression was prominently increased. Therefore, before $6 \mathrm{~h}$ treatment time including $6 \mathrm{~h}$ was chosen to figure out the PI3K/Akt factors in HeLa incubated with
BA because the caspase family activation is relative late in apoptosis process.

The expression level of PI3K (p110a), PI3K (p85), phospho-Akt (Ser473) and phospho-Akt (Thr308) was detected by western blotting after BA treatment at $0,0.5,1$, 2, 3 and 6 h. As presented in Fig. 2B and C, PI3K (p110a) protein level was reduced significantly in BA-treated HeLa cells after $1 \mathrm{~h}$ of incubation $(\mathrm{P}<0.05)$ and the extent of protein activation decreased over time. Consistently, the phospho-Akt (Ser473) and phospho-Akt (Thr308) levels after $2 \mathrm{~h}$ and the PI3K (p85) level after $6 \mathrm{~h}$ significantly changed, indicating that PI3K (p110a) was an upstream regulatory factor that regulated other proteins. The above sequence of BA-induced inhibition was PI3K (p110a) $1 \mathrm{~h}$, phospho-Akt (Ser473) $2 \mathrm{~h}$, phospho-Akt (Thr308) $2 \mathrm{~h}, \mathrm{PI}$ K (p85) 6 h; interestingly, the phosphorylation of p85 was repressed by BA later than phospho-Akt (Ser473), phospho-Akt (Thr308). However, the expression of PI3K (p110a) was still blocked by BA in the beginning, which also can influence the downstream factors: Phospho-Akt (Ser473), phospho-Akt (Thr308) in BA treatment.

To further evaluate the dose-dependent study, a separate set of experiments was performed to determine the above protein activation effected by various concentrations $(0,5$, 10, 20 and $30 \mu \mathrm{mol} / \mathrm{l}$ ) of BA for $6 \mathrm{~h}$ incubation. As shown in Fig. 2D and E, although some proteins showed a fluctuating trend when treated with a small dose, there still had a significant change at $30 \mu \mathrm{mol} / 1 \mathrm{BA}$ treatment. In addition, the authors compared the potency of BA with wortmannin, the inhibitor of PI3K. The observation was the similar to the effect by BA on HeLa cells, suggesting that the PI3K/Akt pathway was involved in BA- induced HeLa apoptosis.

Upregulation of p21 and p27 and the inhibition of the cell cycle in BA-treated HeLa cells. The above results indicated the PI3K/Akt pathway involved in BA induced apoptosis, and the cell cycle is one of the most important processes regulated by the PI3K/Akt signaling pathway for cancer cell proliferation. Therefore, this part was to detect the cell cycle whether involved in BA induction. Treatments of durations were also applied for measuring the expression of $\mathrm{p} 21^{\text {Waf1/Cip1 }}$ and $\mathrm{p} 27^{\mathrm{Kip}}$ proteins, which are important role in inhibition of cell cycle and regulated by Akt. As presented in Fig. 3A, the expression of $\mathrm{p} 27^{\mathrm{Kip}}$ and $\mathrm{p} 21^{\mathrm{Waf} 1 / \mathrm{Cip} 1}$ has an increasing trend, and significantly respective went up after 3 and $2 \mathrm{~h}$ in duration results (Fig. 3B), whereas the level of p21 Waf1/Cip1 phosphorylation reached a plateau and began to decrease after $2 \mathrm{~h}$, indicated a transient phosphorylation pattern in this process. On the other hand, the level of p27 ${ }^{\mathrm{Kip}}$ did not change until $3 \mathrm{~h}$ treatment by BA. The result was consistent with the fact that $\mathrm{p} 21^{\text {Waf1/Cipl }}$ and $\mathrm{p} 27^{\mathrm{Kip}}$ were substrates of the PI3K/Akt pathway because the activation time of $\mathrm{p} 21^{\mathrm{Waf} 1 / \mathrm{Cip} 1}$ and $\mathrm{p} 27^{\mathrm{Kip}}$ was later than pAkt. Conversely, BA treatment of HeLa cells caused a drastic upregulation in the expression of p27 ${ }^{\mathrm{Kip}}$ at 10 , $20 \mu \mathrm{mol} / 1 \mathrm{BA}$ for $6 \mathrm{~h}$ treatment (Fig. 3C and D).

At the same time, the cell cycle was then analyzed by flow cytometry after the cells were treated with $30 \mu \mathrm{mol} / \mathrm{l} \mathrm{BA}$ for various periods ranging up to $48 \mathrm{~h}$. The authors observed that the number of cells in the $\mathrm{S}$ and G2/M phases decreased, and $18-48 \mathrm{~h}$ treatment time caused a dramatically increased G0/G1 phase population compared with in the control 
A

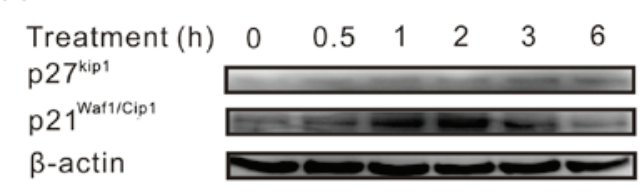

B

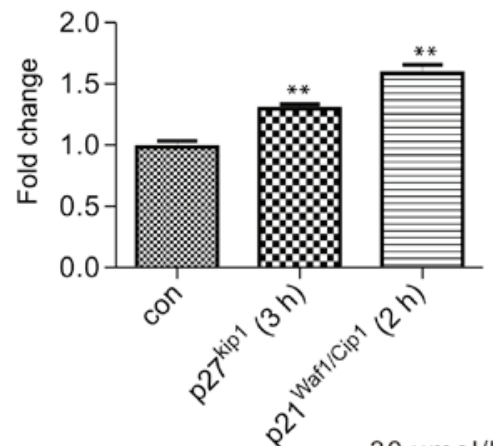

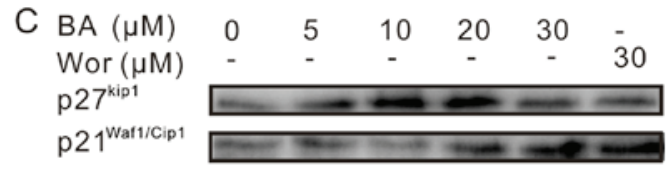

$\beta$-actin

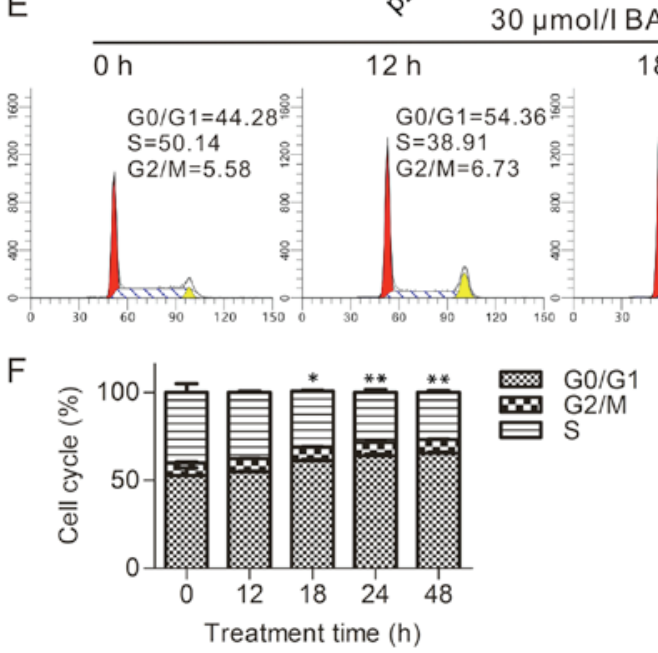

Treatment time $(\mathrm{h})$
D

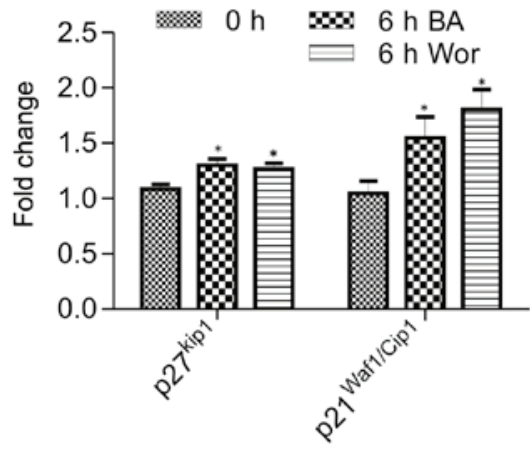

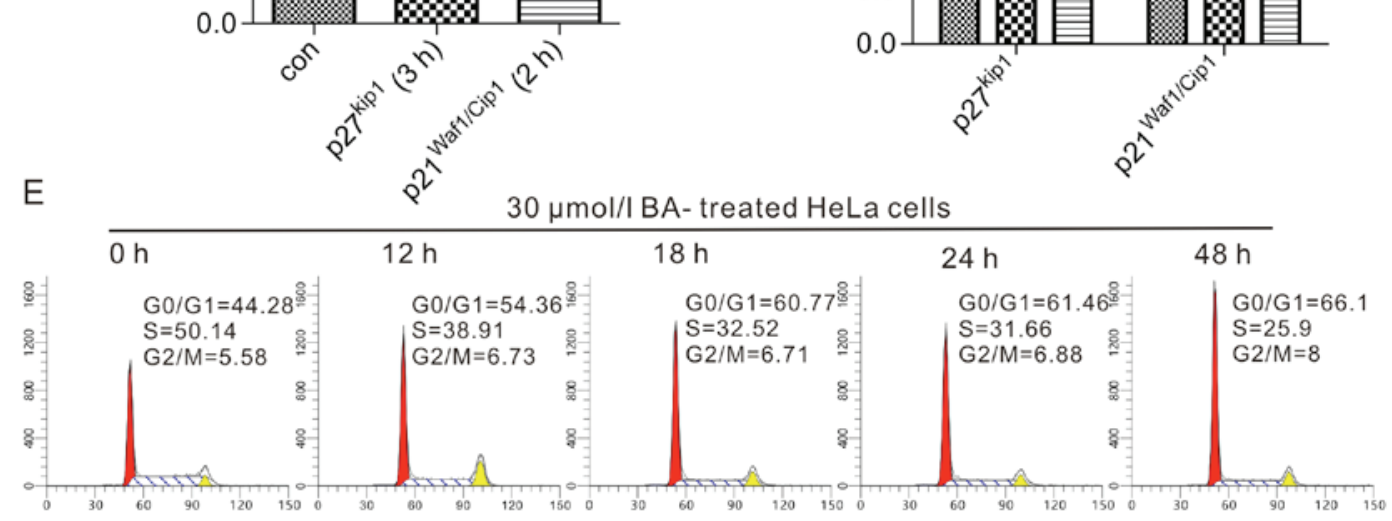

Figure 3. Cell cycle analysis of BA-treated HeLa cells. (A) Important regulator of cell-cycle proteins p27 $7^{\text {Kip }}$, p2 $1^{\text {Wafl/Cipl }}$ was detected by western blotting in time-treatment. (B) Data represented the significant change of initiation time by three independent experiments. (C) Dose treatment was also analyzed


harvested cells were stained with propidium iodide and DNA content analyzed by flow cytometry in various time of BA ( $0-48 \mathrm{~h})$. (F) These histograms were from one out of three representative experiments. Data are presented as mean \pm standard deviation. ${ }^{*} \mathrm{P}<0.05$ and ${ }^{* *} \mathrm{P}<0.01$ vs. control group. BA betulinic acid; Wor, wortmannin; con, control.

group (Fig. 3E and F). Therefore, this result suggested that BA arrested HeLa cells in the G0/G1 phase after the inhibition of the PI3K/Akt pathway depending on the response time.

BA induced mitochondrial-dependent apoptosis and disrupted the mitochondrial membrane potential (MMP) in HeLa cells. Subsequently, we explored whether this effect of BA was associated with an activation of mitochondrial pathway, which was modulated though PI3K/Akt regulated the process of proapoptotic factors, such as the Bcl-2 family and caspase-9.

To investigate the relationship between mitochondrial pathway and the PI3K/Akt pathway, as well as the effect of MMP influenced by BA, we examined the expression level of landmark target caspase-9 and Bad, Bcl-xL which were regulated by Akt. The results demonstrated that $30 \mu \mathrm{mol} / 1$ $\mathrm{BA}$ treatment promoted the expression of Bad after $3 \mathrm{~h}$. Unexpectedly, there were no differences in the level of Bcl-xL, but the ratio of $\mathrm{Bcl}-\mathrm{xL} / \mathrm{Bad}$ protein expression was reduced by BA treatment. This result may have simply been a transposition and needs further investigation (16). Consistently for
Bcl-xL, no alterations in expression levels have been reported upon exposure to BA in other cancer cells (17). Detectable cleavage products of caspase- 9 clearly increased after $3 \mathrm{~h}$ in a time treatment trail (Fig. 4A and B). Therefore, this finding indicated that mitochondrial pathway took the initiative to regulate the apoptosis by BA treatment.

The role of the mitochondrial permeability transition (PT) pore was essential in apoptosis signaling. Opening of the PT pore resulted in membrane depolarization and finally lead to cell apoptosis. In the present study, the HeLa cells were treated with $30 \mu \mathrm{mol} / 1 \mathrm{BA}$ and subsequently stained with JC-1 to test the effect of PT depolarization by BA. JC-1 predominantly existed in monomeric form in cells with depolarized mitochondria and displayed green fluorescence. If with polarized mitochondria, JC-1 primarily formed aggregates in cells and showed reddish-orange fluorescence. The green and the red fluorescence gradually changed, with the green fluorescence significantly increasing during the treatment (data not shown). Changes in the ratio of JC-1 forms (monomeric form/aggregate form) were analyzed and graphically documented to 


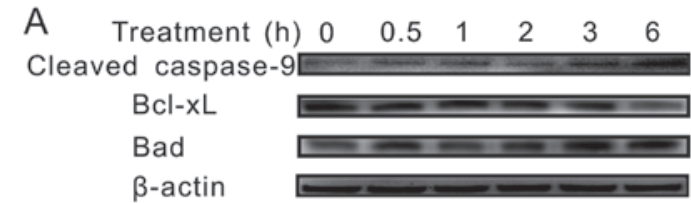

B

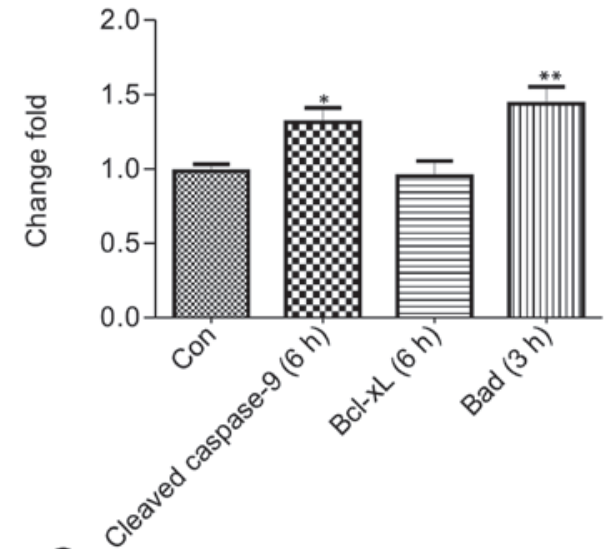

C

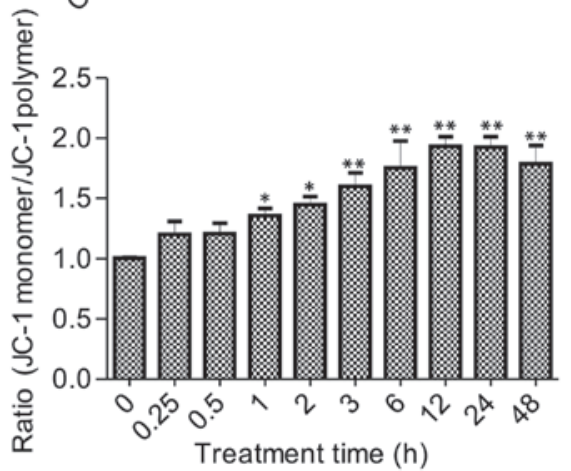

D

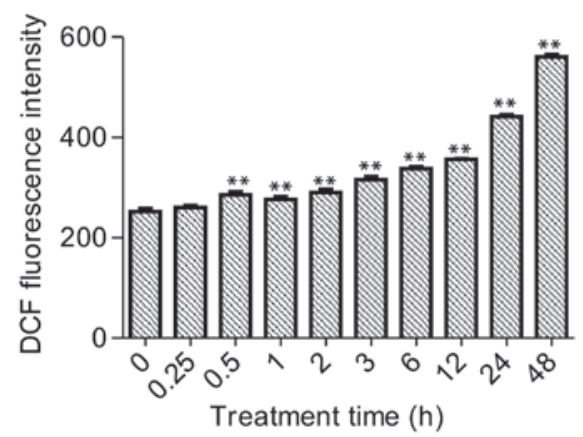

Figure 4. BA promoted mitochondrial damage and induced ROS generation. (A) Results depicted an alternation in mitochondrial-related proteins Bad, Bcl-xL and cleaved caspase- 9 expression in a time-dependent manner. (B) The initiation change time of above proteins in $30 \mu \mathrm{mol} / 1 \mathrm{BA}$ were analyzed. (C) HeLa cells were treated for various time (0-48 h) of BA with $30 \mu \mathrm{mol} / 1$ and subjected to flow cytometric analysis for determination of mitochondrial membrane potential stained by JC-1, bars represented ratio of JC-1 monomer/JC-1 polymer. Data represented three independent experiments, and are presented as mean \pm standard deviation. (D) After the treatment of $30 \mu \mathrm{mol} / 1 \mathrm{BA}$ to HeLa cells, a subsequent increase in generation of ROS in a time-dependent manner. ROS continued to be released throughout the experimental period of $48 \mathrm{~h}$. ${ }^{*} \mathrm{P}<0.05$ and ${ }^{* *} \mathrm{P}<0.01$ vs. control group. BA, betulinic acid; ROS, reactive oxygen species; DCF, 2',7'-dichlorofluorescein.

demonstrate significant changes at $1 \mathrm{~h}$ with $30 \mu \mathrm{mol} / 1 \mathrm{BA}$ treatment (Fig. 4C). Strikingly, in HeLa cell, it was clearly observed that BA triggered the PT pore in a time-dependent way.

BA induced intracellular ROS generation. These observations indicated ROS scavenging probably involved in apoptosis induced by BA because the mitochondrial depolarization was always affected by ROS. To clarify whether ROS was related to the mitochondrial pathway, the ROS generation was detected using an oxidation-sensitive fluorescent dye, DCFH-DA, to determine the starting ROS generation time. As demonstrated in Fig. 4D, ROS generation was enhanced in a time-dependent manner with BA treatment, and the initiation of ROS production had a significant 1.2-fold increase compared to the control at $30 \mathrm{~min}$. Furthermore, the trend was rising at the treatment time and arrived 1.5-fold compared to the control group at $48 \mathrm{~h}$. Combined with above results, ROS generation was initiated earlier than MMP decrease, which suggested that ROS was upstream to regulate the apoptosis by BA, at least in HeLa cells.

Antioxidants prevented PI3K and Akt phosphorylation and apoptosis induction. The authors assessed the potential ability of PI3K/Akt to protect HeLa cells from apoptosis, focusing on its interventions upstream and downstream of ROS events. To unravel the molecular mechanism involved in ROS accumulation and explore the relationship between the ROS and the PI3K/Akt pathway, GSH (ROS inhibitor) was used to pretreatment of HeLa cells before treatment with $30 \mu \mathrm{mol} / 1 \mathrm{BA}$ for $6 \mathrm{~h}$. According to the previous result, $6 \mathrm{~h}$ was the appropriate time because the expression of tested proteins had changed by BA treatment at $6 \mathrm{~h}$. As Fig. 5A and B shown the GSH prevented the BA-induced inhibition of PI3K (p110a) and phosphoAkt (Ser473), meanwhile this change in the PI3K and Akt phosphorylation pattern correlated with the effects on other downstream substrates (p27 $\left.7^{\mathrm{Kip}}, \mathrm{p} 21^{\text {Wafl/Cipl}}\right)$ and mitochondrial proteins (cleaved caspase-9, Bad) comparison with control cells (Fig. 5C and D). Therefore, these results suggested that ROS was upstream factor that could regulate the PI3K/Akt signaling pathway and the mitochondrial pathway.

To further ascertain the relevance between apoptosis and ROS, we pre incubated HeLa cells with $30 \mathrm{mM} \mathrm{GSH}$ before the $30 \mu \mathrm{mol} / 1 \mathrm{BA}$ treatment for $24 \mathrm{~h}$. As presented in Fig. 5E and F, the apoptosis of cells treated with GSH before BA was inhibited significantly $(\mathrm{P}<0.05)$ compared to the positive control just incubated with GSH.

These results supported that ROS was an important factor for regulating the PI3K/Akt signaling pathway and the mitochondrial pathway involved in the BA-induced apoptosis mechanism.

\section{Discussion}

The aim of the present study was to elucidate the molecular mechanisms of apoptosis effects of BA and explore the specific cellular targets or signaling pathways in HeLa cells. As noted in previous studies, BA could induce HeLa apoptosis (14); however, the molecular mechanisms of this process are not fully understood.

A concentration of $30 \mu \mathrm{mol} / 1 \mathrm{BA}$ was chosen for subsequent treatments of HeLa cells to study the apoptosis initiation by BA. Different screening methods demonstrated that BA exhibited a cytotoxic activity in a time-dependent manner in the present study. The growth of the HeLa cells was significantly inhibited after $12 \mathrm{~h}$ treatment (Fig. 1B), and the typical morphology of apoptosis was also showed after $12 \mathrm{~h}$ treatment (Fig. 1C). Meanwhile, $12 \mathrm{~h}$ was the apoptosis initiation 

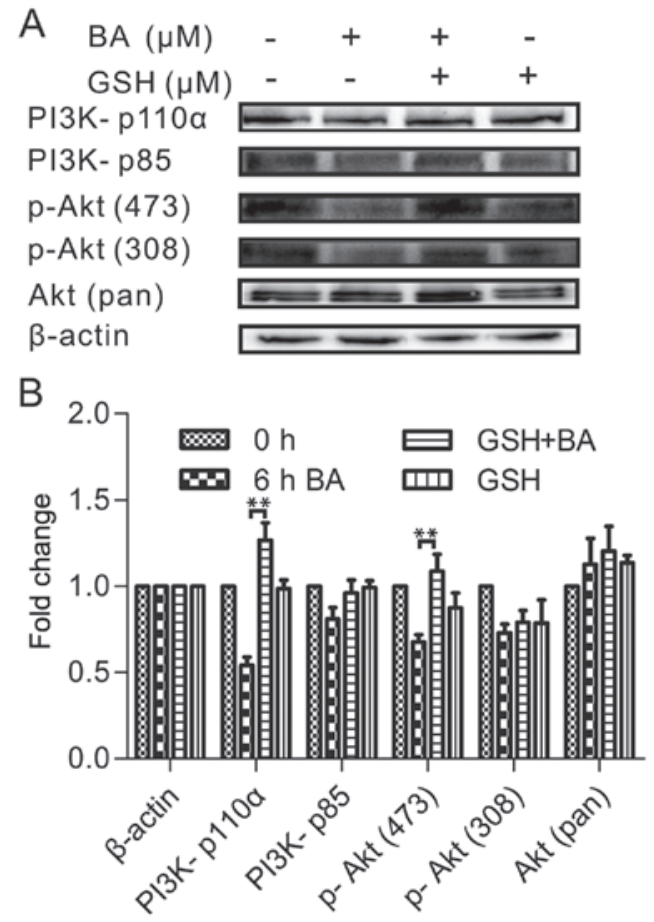

E
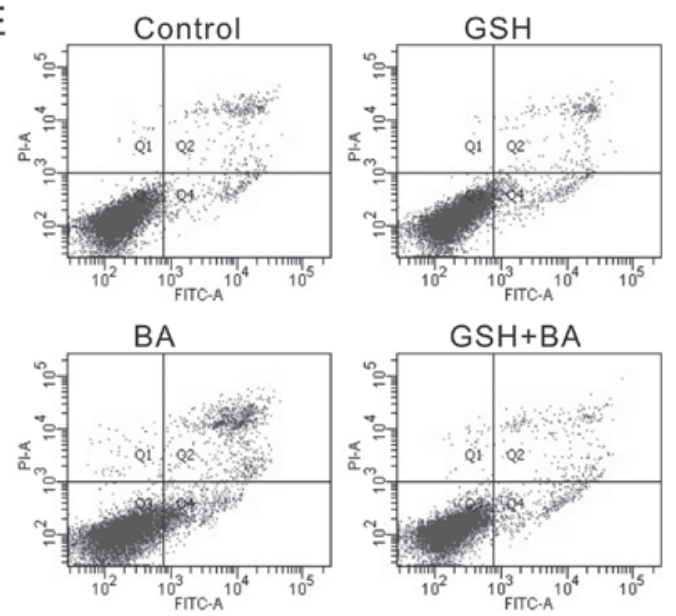

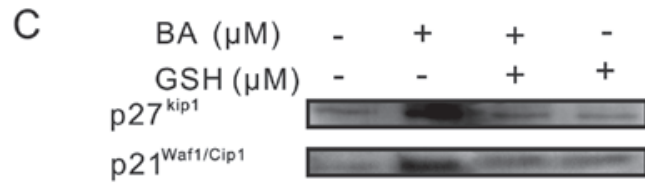

Cleaved caspase-9 $\mathrm{BCl}-\mathrm{xL}$

Bad

$\beta$-actin
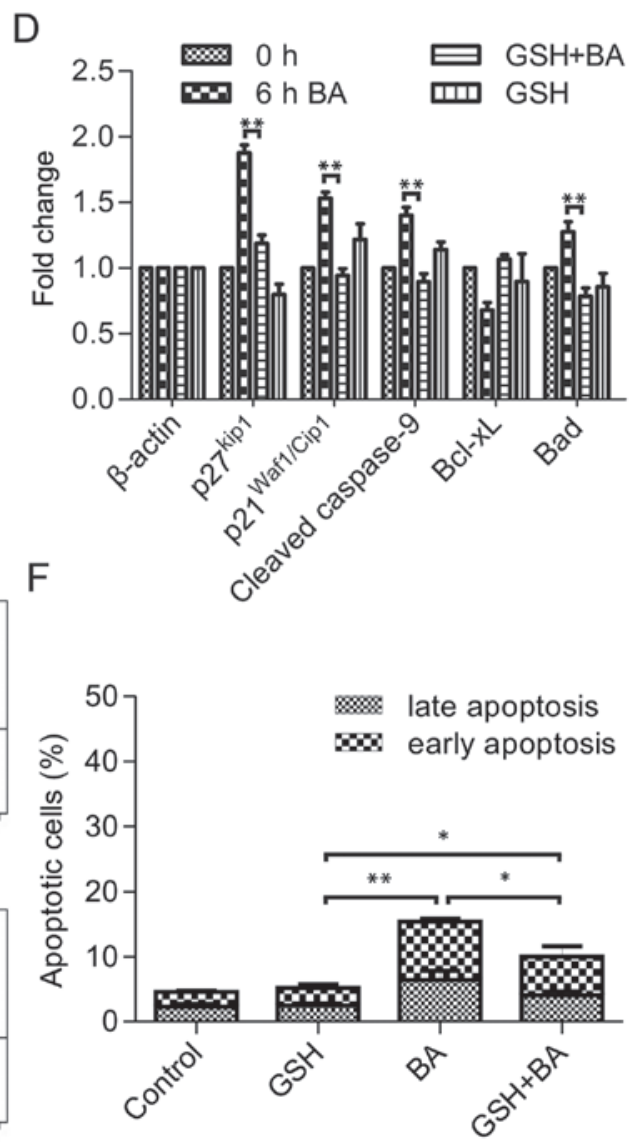

Figure 5. Pharmacological inhibitors affected the level of different signaling molecules and apoptosis rate. (A) Western blot analyses showing the effects of antioxidant GSH on PI3K/Akt phosphorylation. GSH $(30 \mathrm{mM})$ was pre-incubated with HeLa cells for $1 \mathrm{~h}$ before treatment with $30 \mu \mathrm{mol} / 1 \mathrm{BA}$ for $6 \mathrm{~h}$. (B) The values of the above-mentioned proteins are represented as the means $\pm \mathrm{SD}, \mathrm{n}=3 .{ }^{* * *} \mathrm{P}<0.01$ compared to the control group. (C) The same method was applied to detect the level of downstream substrates. (D) The values of the above-mentioned proteins are represented as the means $\pm \mathrm{SD}, \mathrm{n}=3$. ${ }^{* *} \mathrm{P}<0.01$ compared to the control group. (E) Analysis of Annexin V-FITC flow cytometry results exemplifying the different levels of protective effect afforded by $30 \mathrm{mM}$ GSH. HeLa cells were first incubated with the indicated test substance for $1 \mathrm{~h}$ followed by treatment with $30 \mu \mathrm{mol} / 1 \mathrm{BA}$ for $24 \mathrm{~h}$. (F) Measurement of apoptotic cell percentage following treatment. Values are expressed as the means \pm standard deviation, $n=3$. "P<0.05 and ${ }^{* *} \mathrm{P}<0.01$ as indicated. GSH, glutathione; FITC, fluorescein isothiocyanate; BA betulinic acid.

time of HeLa cells exposed to $30 \mu \mathrm{mol} / 1 \mathrm{BA}$ because it caused a significant increase of apoptosis cells at $12 \mathrm{~h}$ (Fig. 1D and E). Therefore, $12 \mathrm{~h}$ is a critical treatment time to induce inhibition, and it was assumed that the relevance factors involved in apoptosis process should be activated by BA before $12 \mathrm{~h}$.

BA appears to target the mitochondrial PT pore directly in most previous results (6), thus, the authors firstly figured out the expression level of cleavage caspase- 9 to find an appropriate monitor time for other proteins, because the caspase- 9 is crucial for mitochondrial pathway and its activation is relative later than other proteins. As Fig. 2A indicated, after $6 \mathrm{~h}$ treatment with $30 \mu \mathrm{mol} / 1 \mathrm{BA}$, the expression of cleaved caspase- 9 was prominently increased, thus, before and including $6 \mathrm{~h}$ treatment time was chosen to detect the PI3K/Akt signaling factors.
The PI3K/Akt signaling pathway represents an important anticancer target especially for mitochondrial apoptosis because the regulation of mitochondrial respiratory activities was affected by Akt through protein translation pathway $(15,18,19)$. Growth factors and hormones trigger a PI3K phosphorylation event, which, in turn, coordinates cell growth, cell cycle entry, cell migration and cell survival (20). In addition, the PI3K pathway exerts its function through the downstream molecule Akt to regulate various cell functions, including cell proliferation, cell transformation, cell apoptosis, tumor growth and angiogenesis (20). Given the significant role of PI3K/Akt in cancer cells, the authors determined whether BA treatment changed the PI3K expression and the phosphorylation status of Akt in HeLa cells. 


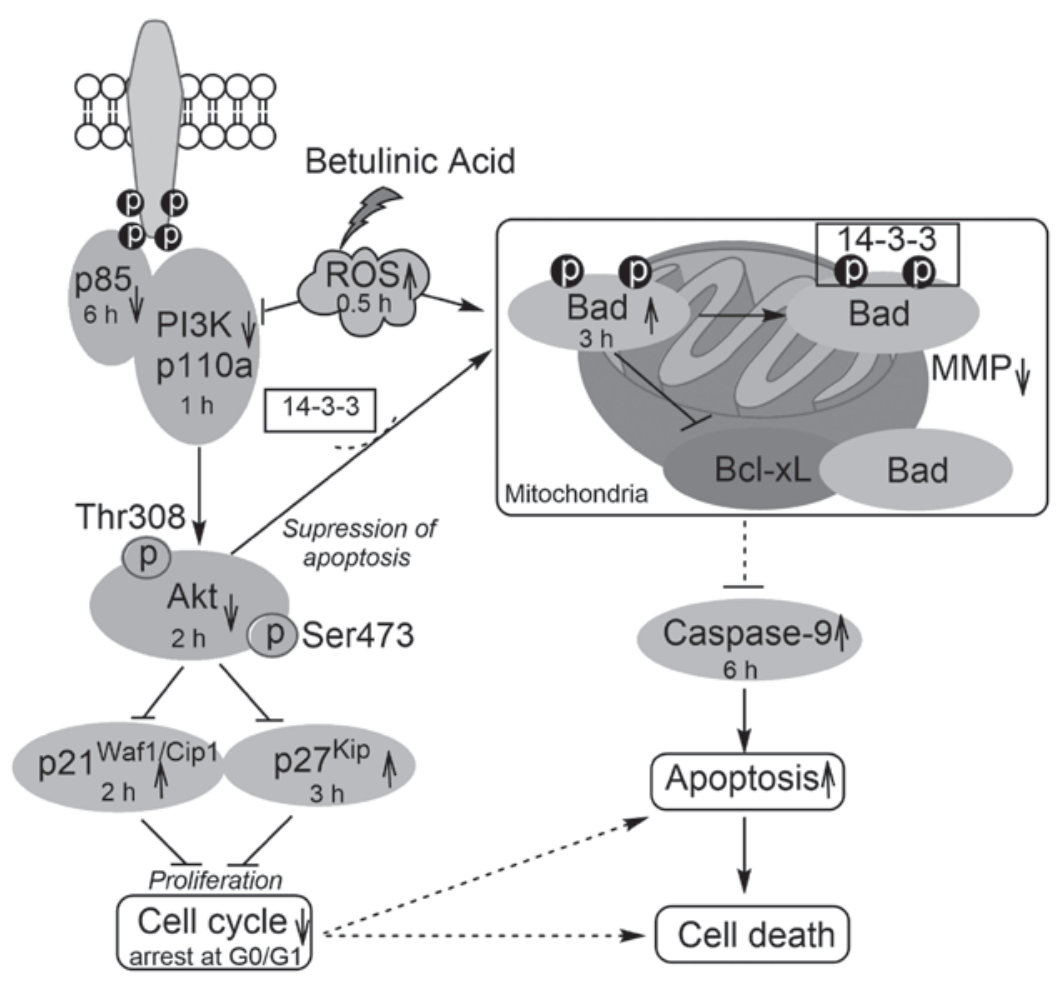

Figure 6. A representation of signaling molecules involved in HeLa cell apoptosis induced by betulinic acid.

Western blotting was used to verify phosphorylation of PI3Ks' catalytic subunit (p110) and an adapter subunit (p85), which induces the phosphorylation of Akt at two key regulatory sites: Threonine 308 (Thr308) and serine 473 (Ser473) (21). These proteins were inhibited in does- and time-treatment (Fig. 2). Although some proteins showed a fluctuating trend when treated with a small dose, Fig. $2 \mathrm{C}$ and D still suggested that BA could inhibit the PI3K/Akt signaling pathway in a relative does- dependent manner in early time.

The Akt protein modulates cyclin-dependent kinase inhibitors, $\mathrm{p} 27^{\mathrm{Kip}}$ and $\mathrm{p} 21^{\text {Waf1/Cip1 }}$, that inhibit cell cycle progression (22). In addition, Akt has been implicated as an anti-apoptotic factor in many different cell death processes (e.g., Akt regulates the apoptotic machinery and inactivates proapoptotic proteins, such as Bad, which controls the release of cytochrome $c$ from mitochondria) $(12,23)$. Therefore, the authors designed two parts to measure the cell cycle and mitochondrial pathway.

For cell cycle part, as shown in Fig. 3A and B, although the protein expression continuously increased with time, the BA treatment of HeLa cells caused a drastic upregulation in the expression of $\mathrm{p} 21^{\text {Wafl/Cipl }}$ and $\mathrm{p} 27^{\text {Kip }}$ proteins after the inhibition of the phosphorylation of pAkt (Fig. 3A); this finding is consistent with the fact that $\mathrm{p} 21^{\text {Wafl/Cipl }}$ and $\mathrm{p} 27^{\text {Kip }}$ are substrates of the PI3K/Akt pathway (24). The flow cytometry result indicated that BA arrested HeLa cells in the G0/G1 phase after the inhibition of the PI3K/ Akt pathway; this finding is in line with the protein expression profile of $\mathrm{p} 21^{\text {Wafl/Cipl }}$ and $\mathrm{p} 27^{\text {Kip }}$ can arrest cell proliferation at the G1/S transition (25). Actually, numerous lines of evidence have indicated that anticancer drugs induce tumor regression through the induction of cell cycle arrest and/or apoptosis (26,27), and Kang et al (28) also proved that the PI3K/Akt pathway is involved in the apoptosis process by thioridazine. The present observations suggested that the inhibition of the PI3K/Akt pathway by BA in HeLa cells led to cell cycle arrest.

At the same time, in the apoptotic process, the mitochondrial pathway is a central event that seals the cell's fate, and it is particularly important for BA-induced apoptosis $(6,29)$. BA has been reported to induce apoptosis via direct mitochondrial perturbations of Bcl-2 family proteins, such as antiapoptotic Bcl-xL and proapoptotic Bad $(29,30)$. As noted in the authors' previous studies, the 14-3-3 protein was inhibited in HeLa cells by BA (14), and the interaction between Bad and 14-3-3 causes $\mathrm{Bad}$ to be retained in the cytoplasm, thus preventing Bad from dimerizing with $\mathrm{Bcl}-\mathrm{xL}$ at the mitochondria and mediating the release of Bax from Bcl-xL. Moreover, the PI3K/Akt signaling pathway phosphorylates Bad at Ser155 in the BH3 domain that plays a critical role in blocking the dimerization of Bad and Bcl-xL (17,31). Therefore, Bad and Bcl-xL were measured to evaluate the relationship among these proteins by western blotting for treatments of durations. Because of caspase-9 significantly increasing after $6 \mathrm{~h}$ (Fig. 4), the authors also examined caspase-9 influenced by Akt because previous research demonstrated the involvement of the PI3K/Akt pathway in the suppression of the cytochrome $c$-induced processing of pro-caspase- 9 and reduced caspase activity (32).

To better understand the effectiveness of BA in targeting the mitochondria of HeLa cells, alterations in the MMP were directly determined. Loss of MMP is a near-universal hallmark and a critical step for subsequent cell death $(3,33)$. Thus, the result (Fig. 4C and D) showed that the mitochondria pathway was involved in the effects of the BA treatment of HeLa cells. At the same time, ROS played an important role in apoptosis induction because it is involved in MMP and cell death induction $(34,35)$. Hence, the generation of ROS was 
monitored. Combined with activation time point, the decrease in MMP started from $1 \mathrm{~h}$ of treatment after the generation of ROS $0.5 \mathrm{~h}$, confirming that the loss of MMP may be due to an increased ROS level. These data illustrated the role of BA in enhancing ROS and inducing apoptotic death in HeLa cells. The generation of ROS, which induced disruption of mitochondrial function with a concurrent loss of MMP, was important for the BA-treatment effects on HeLa cells.

The results described above suggested that ROS played a prominent role in BA-induced apoptosis and that PI3K/Akt was also influenced by BA at an early time. Therefore, we then investigated the relationship between ROS and the PI3K/Akt signaling pathway. GSH is the key antioxidative regulator of intracellular redox status and is commonly used to antagonize the effects of ROS or to protect against programmed cell death $(36,37)$. Therefore, GSH was selected to investigate the importance of ROS in the apoptosis process mediated by BA. Western blot results supported that ROS was an important upstairs factor for regulating the PI3K/Akt signaling pathway and the mitochondrial pathway, as Fig. 5 indicated, PI3K (p110a), phospho-Akt (Ser473), p27 ${ }^{\text {Kip }}$, p21 $1^{\text {Waf1/Cip1 }}$, caspase-9 and Bad were protected by GSH. At the same time, GSH could prevent HeLa cells apoptosis that supposes that ROS was a critical regulator for apoptosis in BA treatment (Fig. 5E and F). These results supported the view that PI3K/Akt signaling and the mitochondrial pathway were regulated by ROS and acted in opposition in the balance of cell survival and death.

In conclusion, BA showed a strong inhibitory effect on HeLa cell growth at pharmacological concentration $(30 \mu \mathrm{mol} / \mathrm{l})$. The present study confirmed that BA-induced apoptosis involved the inhibition of PI3K (p110a and p85), presented the deregulation of the Akt signaling pathway in response to the generation of ROS, indicated that there is a decrease in the mitochondrial potential, the activation of mitochondrial-regulated Bad, caspase- 9 and the cell cycle regulators $\mathrm{p} 27^{\mathrm{Kip}}$ and $\mathrm{p} 21^{\mathrm{Waf} 1 / \mathrm{Cip} 1}$ and the induction of G0/G1 phase arrest (Fig. 6). These insights may be helpful to understand the molecular mechanism of the BA antitumor effect in HeLa cells and to enhance the development of BA for clinical use.

\section{Acknowledgements}

The present study was financially supported by the Fundamental Research Funds for the Central Universities (grant no. DL13EA02).

\section{References}

1. Pisha E, Chai H, Lee IS, Chagwedera TE, Farnsworth NR, Cordell GA, Beecher CW, Fong HH, Kinghorn AD, Brown DM, et al: Discovery of betulinic acid as a selective inhibitor of human melanoma that functions by induction of apoptosis. Nat Med 1: 1046-1051, 1995.

2. Zuco V, Supino R, Righetti SC, Cleris L, Marchesi E, GambacortiPasserini C and Formelli F: Selective cytotoxicity of betulinic acid on tumor cell lines, but not on normal cells. Cancer Lett 175: 17-25, 2002.

3. Kroemer G, Galluzzi L and Brenner C: Mitochondrial membrane permeabilization in cell death. Physiol Rev 87: 99-163, 2007.

4. Rabi T, Shukla S and Gupta S: Betulinic acid suppresses constitutive and TNFalpha-induced NF-kappaB activation and induces apoptosis in human prostate carcinoma PC-3 cells. Mol Carcinog 47: 964-973, 2008.
5. Eichenmüller M, von Schweinitz D and Kappler R: Betulinic acid treatment promotes apoptosis in hepatoblastoma cells. Int J Oncol 35: 873-879, 2009.

6. Tan DF, Li Q, Rammath N, Beck A, Wiseman S, Anderson T, al-Salameh A, Brooks J and Bepler G: Prognostic significance of expression of p53 oncoprotein in primary (stage I-IIIa) non-small cell lung cancer. Anticancer Res 23: 1665-1672, 2003.

7. Mullauer FB, Kessler JH and Medema JP: Betulinic acid induces cytochrome $c$ release and apoptosis in a Bax/Bak-independent, permeability transition pore dependent fashion. Apoptosis 14: 191-202, 2009.

8. Eichenmüller M, Hemmerlein B, von Schweinitz D and Kappler R: Betulinic acid induces apoptosis and inhibits hedgehog signalling in rhabdomyosarcoma. Br J Cancer 103: 43-51, 2010

9. Cheng L, Xia TS, Wang YF, Zhou W, Liang XQ, Xue JQ, Shi L, Wang Y and Ding Q: The apoptotic effect of D Rhamnose $\beta$-hederin, a novel oleanane-type triterpenoid saponin on breast cancer cells. PLoS One 9: e90848, 2014.

10. Kim JA, Åberg C, de Cárcer G, Malumbres M, Salvati A and Dawson KA: Low dose of amino-modified nanoparticles induces cell cycle arrest. ACS Nano 7: 7483-7494, 2013.

11. Liang QH, Liu Y, Wu SS, Cui RR, Yuan LQ and Liao EY: Ghrelin inhibits the apoptosis of MC3T3-E1 cells through ERK and AKT signaling pathway. Toxicol Appl Pharmacol 272: 591-597, 2013.

12. Datta SR, Dudek H, Tao X, Masters S, Fu H, Gotoh Y and Greenberg ME: Akt phosphorylation of BAD couples survival signals to the cell-intrinsic death machinery. Cell 91: 231-241, 1997.

13. Roy B, Pattanaik AK, Das J, Bhutia SK, Behera B, Singh P and Maiti TK: Role of PI3K/Akt/mTOR and MEK/ERK pathway in Concanavalin A induced autophagy in HeLa cells. Chem Biol Interact 210: 96-102, 2014.

14. Xu T, Pang Q, Zhou D, Zhang A, Luo S, Wang Y and Yan X: Proteomic investigation into betulinic acid-induced apoptosis of human cervical cancer HeLa cells. PLoS One 9: e105768, 2014.

15. Meinig JM and Peterson BR: Anticancer/antiviral agent Akt inhibitor-IV massively accumulates in mitochondria and potently disrupts cellular bioenergetics. ACS Chem Biol 10: 570-576, 2015.

16. Ma K, Liu Y, Zhu Q, Liu CH, Duan JL, Tan BK and Zhu YZ: H2S donor, S-propargyl-cysteine, increases CSE in SGC-7901 and cancer-induced mice: Evidence for a novel anti-cancer effect of endogenous H2S? PLoS One 6: e20525, 2011.

17. Willis SN, Chen L, Dewson G, Wei A, Naik E, Fletcher JI, Adams JM and Huang DC: Proapoptotic Bak is sequestered by Mcl-1 and Bcl-xL, but not Bcl-2, until displaced by BH3-only proteins. Genes Dev 19: 1294-1305, 2005.

18. Tian F, Ding D and Li D: Fangchinoline targets PI3K and suppresses PI3K/AKT signaling pathway in SGC7901 cells. Int J Oncol 46: 2355-2363, 2015.

19. Goo CK, Lim HY, Ho QS, Too HP, Clement MV and Wong KP: PTEN/Akt signaling controls mitochondrial respiratory capacity through 4E-BP1. PLoS One 7: e45806, 2012.

20. Cantley LC: The phosphoinositide 3-kinase pathway. Science 296: 1655-1657, 2002.

21. Thorpe LM, Yuzugullu H and Zhao JJ: PI3K in cancer: Divergent roles of isoforms, modes of activation and therapeutic targeting. Nat Rev Cancer 15: 7-24, 2015.

22. Brazil DP and Hemmings BA: Ten years of protein kinase B signalling: A hard Akt to follow. Trends Biochem Sci 26: 657-664, 2001.

23. del Peso L, González-García M, Page C, Herrera R and Nuñez G: Interleukin-3-induced phosphorylation of BAD through the protein kinase Akt. Science 278: 687-689, 1997.

24. Reed SI: Keeping p27(Kip1) in the cytoplasm: A second front in cancer's war on p27. Cell Cycle 1: 389-390, 2002.

25. Nakayama KI and Nakayama K: Ubiquitin ligases: Cell-cycle control and cancer. Nat Rev Cancer 6: 369-381, 2006.

26. Ortega S, Malumbres M and Barbacid M: Cyclin D-dependent kinases, INK4 inhibitors and cancer. Biochim Biophys Acta 1602: 73-87, 2002.

27. Lee SK, Zhang W and Sanderson BJ: Selective growth inhibition of human leukemia and human lymphoblastoid cells by resveratrol via cell cycle arrest and apoptosis induction. J Agric Food Chem 56: 7572-7577, 2008

28. Kang S, Dong SM, Kim BR, Park MS, Trink B, Byun HJ and Rho SB: Thioridazine induces apoptosis by targeting the PI3K/ $\mathrm{Akt} / \mathrm{mTOR}$ pathway in cervical and endometrial cancer cells. Apoptosis 17: 989-997, 2012. 
29. Rzeski W, Stepulak A, Szymański M, Sifringer M, Kaczor J, Wejksza K, Zdzisińska B and Kandefer-Szerszeń M: Betulinic acid decreases expression of bcl-2 and cyclin D1, inhibits proliferation, migration and induces apoptosis in cancer cells. Naunyn Schmiedebergs Arch Pharmacol 374: 11-20, 2006.

30. Zhang X, Lu H, Wang Y, Liu C, Zhu W, Zheng S and Wan F: Taurine induces the apoptosis of breast cancer cells by regulating apoptosis-related proteins of mitochondria. Int J Mol Med 35: 218-226, 2015.

31. Zou Y, Li Q, Jiang L, Guo C, Li Y, Yu Y, Li Y, Duan J and Sun Z: DNA hypermethylation of CREB3L1 and Bcl-2 associated with the mitochondrial-mediated apoptosis via PI3K/Akt pathway in human BEAS-2B cells exposure to silica nanoparticles. PLoS One 11: e0158475, 2016.

32. Khan I, Guru SK, Rath SK, Chinthakindi PK, Singh B, Koul S, Bhushan S and Sangwan PL: A novel triazole derivative of betulinic acid induces extrinsic and intrinsic apoptosis in human leukemia HL-60 cells. Eur J Med Chem 108: 104-116, 2016.

33. Hamanaka RB and Chandel NS: Mitochondrial reactive oxygen species regulate cellular signaling and dictate biological outcomes. Trends Biochem Sci 35: 505-513, 2010.
34. Behrend L, Henderson G and Zwacka RM: Reactive oxygen species in oncogenic transformation. Biochem Soc Trans 31: 1441-1444, 2003.

35. Deeb D, Gao X, Jiang H, Janic B, Arbab AS, Rojanasakul Y, Dulchavsky SA and Gautam SC: Oleanane triterpenoid CDDO-Me inhibits growth and induces apoptosis in prostate cancer cells through a ROS-dependent mechanism. Biochem Pharmacol 79: 350-360, 2010.

36. Chandel NS: Mitochondrial complex III: An essential component of universal oxygen sensing machinery? Respir Physiol Neurobiol 174: 175-181, 2010.

37. Chandel NS: Mitochondrial regulation of oxygen sensing. Adv Exp Med Biol 661: 339-354, 2010.

(i) (9) This work is licensed under a Creative Commons

c) At NG ND Atribution-NonCommercial-NoDerivatives 4.0 International (CC BY-NC-ND 4.0) License. 